\title{
Farming with alternative pollinators increases yields and incomes of cucumber and sour cherry
}

\author{
Stefanie Christmann ${ }^{1}$ - Aden Aw-Hassan ${ }^{2}$. Toshpulot Rajabov ${ }^{3}$. \\ Aloviddin S. Khamraev ${ }^{4}$ Athanasios Tsivelikas ${ }^{1}$
}

Accepted: 2 June 2017 / Published online: 30 June 2017

(C) INRA and Springer-Verlag France SAS 2017

\begin{abstract}
Pollinator decline is acknowledged worldwide and constitutes a major subject of environmental research. Nevertheless, farmers' efforts to protect pollinators in agricultural lands remain very limited, in particular if no compensation scheme is applicable. Current research focuses on measuring pollinator diversity in different landscapes, but research on income gains, due to habitat enhancement and high pollinator diversity, may have greater potential to induce farmers' field management changes. In 2012, it was suggested for the first time that farmers' motivation would be triggered if the demonstration was made that enhancing pollinator habitats, with a novel approach of farming with alternative pollinators, can increase yield and income. In 2013-2014, therefore, a 18month-pilot project was set on a participatory basis in Uzbekistan, to test this farming with alternative pollinators approach on field and orchard crops. The practicability and the potential of the approach were tested in collaboration with seven smallholders, two commercial farmers, and two schools. We analyzed the yield and insect diversity (pollinators, predators, and pests) of seven cucumber fields in the Parkent district and four orchards of sour cherry in the Boysun district in Uzbekistan. Here we show that the fields with enhanced habitats faced higher diversity of pollinators and predators, but less pests than control fields. Furthermore,
\end{abstract}

Stefanie Christmann

s.christmann@cgiar.org

ICARDA, B.P. 6299, 10112 Rabat, Morocco

ICARDA, POB 950764, Amman, Jordan

Samarkand State University, Samarkand, Uzbekistan 140104

4 Research Institute of Gene Pool of Plants and Animals of Uzbek Academy of Sciences, Tashkent, Uzbekistan 100053 the farming with alternative pollinators approach doubled the yield of sour cherry in 2014 and highly increased the income from cucumber in 2013. In 2014, however, a climatic disaster influenced the results on cucumber in Parkent district. Ultimately, $94 \%$ of the farmers were willing to enhance pollinator habitats after being informed of these higher-yield figures. If more projects confirm that farming with alternative pollinators creates an economically self-sustaining incentive for farmers to improve habitats, this approach could contribute considerably to global pollinator protection and food security.

Keywords Agriculture · Habitat enhancement · Income · Knowledge $\cdot$ Self-supporting

\section{Introduction}

\subsection{Concern for pollinators}

Globally, the diversity of pollinators has been declining rapidly for decades, particularly in agricultural landscapes (Biesmeijer et al. 2006; Potts et al. 2010; IPBES 2016). Apparently, general awareness is low concerning the fact that wild pollinators provide about $85 \%$ of the global pollination services (Nabhan and Buchmann 1997). Honeybees cannot compensate for the loss of diversity of wild pollinators (Garibaldi et al. 2013). Climate change increases risks for pollinators (Christmann and Aw-Hassan 2012; Potts et al. 2010).

Besides the achievements of environmental nongovernmental organizations, notably Xerces Society, efforts to protect pollinators are mainly at the stage of research (IPBES 2016). The European Union pays costly and controversial subsidies ( $€ 22.2$ bn for the period 2007-2013) for environmental schemes (McCracken et al. 2015), but to date, no 
country has an economically self-supporting protection strategy across sectors, which is implemented by a mass basis of local people.

In Central Asia, awareness of threats to wild pollinators is low, despite the fact that Central Asia has been identified economically as the second most vulnerable area globally in case of pollinator loss (Gallai et al. 2009; IPBES 2016). Uzbekistan does not have a policy for pollinator protection. Uzbekistan has been expanding the total area of horticulture crops for almost 10 years. Fields and orchards are established close to urban areas on former rangelands, resulting in altered landscapes of entire districts. In Parkent district close to the capital Tashkent, this policy is destroying many important elements of pollinator habitats like hedgerows, dead wood, areas without tillage, and forage during three seasons. In the remote mountainous Boysun district in the south of Uzbekistan, this horticulture policy is implemented in an already degraded environment to augment national fruit production and to generate income opportunities. Orchards have usually only one crop and bare soil, which is plowed regularly, so that most of the year, wild pollinators find neither nectar nor pollen nor nesting material and sites or shelter. Often, fields encompass several hectares for one crop.

\subsection{The importance of wild pollinators}

Pollinators have essential key functions in four aspects, namely

1. Agriculture: Most high-value crops require or benefit from pollinators. Globally, the economic value of pollination by bees and other insects was estimated to be $€ 153$ billion in 2005 for the main food crops (Gallai et al. 2009). Loss of pollinators can endanger food security (Chaplin-Kramer et al. 2014; Gallai et al. 2009; Klein et al. 2007).

2. Biodiversity of species and habitats: $87 \%$ of all flowering plants need a pollinator (Ollerton et al. 2011). Pollination is a precondition for diversity of plant species and indirectly also of fauna and habitats. Loss of pollinators can cause a cascade of extinctions (Biesmeijer et al. 2006) and sudden collapse of pollinator communities (Lever et al. 2014).

3. Climate change adaptation: Cross-pollination can enrich genetic diversity, which could result in new genotypes more advantageous regarding climate change effects (Christmann and Aw-Hassan 2012). Without cross-pollination, the climate change-induced extinction rates might accelerate rapidly.

4. Other ecosystem services: As $87 \%$ of all flowering plants require insect pollination (Ollerton et al. 2007), all other ecosystem services rely to some extent on pollination, namely the percentage of ecosystem services provided by these $87 \%$ of flowering plants. It is unlikely that the remaining species can compensate the ecosystem services provided by those plants.

\subsection{Pollinator protection focusing on farmers as target group}

Research on pollination is predominantly a domain of entomological, environmental, and agro-ecological research and rarely linked to farmers in developing or transforming economies (Christmann and Aw-Hassan 2012). The pollination crisis is a consequence of human actions, short-term priorities, and decisions, but social science rarely contributes to the analysis of this global problem and to the development of problem-solving approaches. Little is known about villagers' and farmers' knowledge about wild pollinators, their habitat requirements, the value of pollination services, and potential yield gains by enhanced pollination (Hanes et al. 2013; Kasina et al. 2009; McCracken 2015; Munyuli 2011). According to these case studies, pollination is mostly regarded as a free service. This lack of recognition of the value of wild pollinators is a risk factor for these species.

Most wild pollinators work in a small area of approximately 50-2000-m radius of the nest (Garibaldi et al. 2014; Kohler et al. 2008; Ricketts et al. 2008). In nearly the entire terrestrial area of our planet, they require villagers to protect and enhance habitats at the farm and landscape level. Even highincome countries cannot afford to continuously subsidize broad pollinator protection programs, e.g., for seeding wildflower strips or paying compensation for sustaining diverse field edges. Payments for ecosystem services (PES) are not realistic on a global scale. If breeders develop more pollinatorindependent crops to prevent malnutrition (Chaplin-Kramer et al. 2014), the risks (lack of nectar and pollen) for indigenous pollinators might increase.

Some authors recommend provision of information on the importance of pollinator protection to farmers and local people (Hanes et al. 2013; Kasina et al. 2009; McCracken et al. 2015; Munyuli 2011). The majority of publications promote wildflower strips to be seeded by farmers for pollinator protection purposes. Some authors assume that such strips might also allow yield increase (e.g., Blaauw and Isaacs 2014; Feltham et al. 2015; Garibaldi et al. 2014; Pywell et al. 2015).

Do these approaches sufficiently address farmers' needs and preferences to prove successful on a large scale? Farms are business entities mostly giving priority to high income. Field margins are often scarce or not available at all in agroindustrial landscapes (Feltham et al. 2015). Farmers tend to maximize the use of land, their capital to produce crops to generate income. We assume that successful and selfsupporting pollinator protection by farmers at a larger scale requires 
1. A shift from pollinators as the target group (conservation approach) to farmers as the target group, while pollinators could be actors and beneficiaries (agricultural approach)

2. Evidence-based information on the economic impacts of habitat enhancement

3. Incomes from areas designated to attract and host higher abundance and diversity of pollinators

4. Community-based programs focusing on the habitat requirements of pollinators, their importance and value, potential risks and income options.

\subsection{The FAP approach}

The Farming with Alternative Pollinators (FAP) approach (Christmann and Aw-Hassan 2012) focuses on the interests of farmers to increase their yields, and it involves them in the development of field sketches. The term utilizes "alternative" instead of "wild," because wild has the connotations nature and preservation. FAP is an agricultural approach focusing on production factors and hence on the distinction between managed or domesticated pollinators (honeybees, commercial bumblebees) and those agents of production, which farmers currently do not size. FAP is based on The Economics of Ecosystems and Biodiversity (TEEB 2010) and thus on the demonstration of the economic value of ecosystem services and biodiversity. FAP measures the economic benefit of habitat enhancement attracting a higher diversity and abundance of pollinators and predators.

Christmann and Aw-Hassan (2012) suggest the following stepwise process.

1. Starting with enhanced fields having higher diversity of crops, herbs, spices, medicinal plants (Fig. 1) and nesting support in habitat zones designed for pollinator attraction. Higher total income shall trigger intrinsic motivation of many farmers. In contrast to most TEEB-based approaches, FAP does not require PES systems. The incentive is inherent to the approach; therefore, FAP is scalable.

2. Planting pollinator corridors containing wild fruit tree species, berries, and medicinal plants between enhanced agricultural and natural sites in cooperation with farming communities having already positively experienced step 1.

3. Nationwide assessments of the value of pollination services and of regions with pollinator lack to stimulate cooperation of political stakeholders across sectors.

4. Mainstreaming pollinator protection by national governments.

As FAP fields also attract a higher number of diverse predators, the impact on pest control should be assessed to create

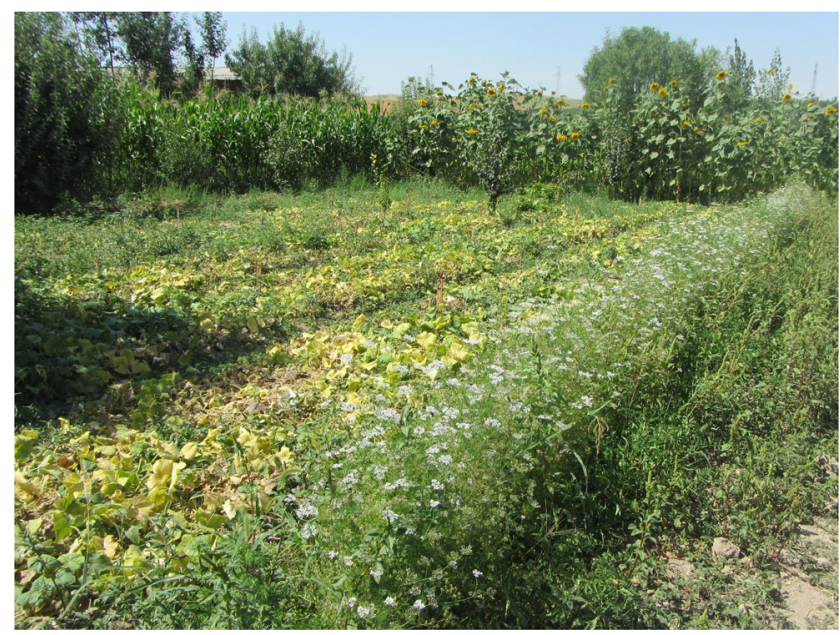

Fig. 1 FAP-02 field in Parkent 2014: field borders of coriander and sunflower attracted diverse pollinators and ensured that cucumber plants sustaining aphids received good pollination

an incentive for reduced use of chemicals. This could additionally contribute to pollinator protection.

Local people enhancing local habitats are key actors in pollinator protection. Finding an entry point to change local peoples' perceptions and behavior is possibly a precondition for success in pollinator protection. One objective of this article is to argue not only for pollinator-friendly agriculture as done by the mainstream of respective research (e.g., Blaauw and Isaacs 2014; Feltham et al. 2015; Garibaldi et al. 2014; Pywell et al. 2015), but also for farmer-friendly pollinator protection and more focus on the values of humans. Based on better understanding, local farmers could employ multiple approaches, e.g., wildflower strips, diverse hedges, or FAP. We hypothesized that the income from $75 \%$ of the area of the FAP field would be higher than from the entire control field. Additionally, the farmer would have some income from the habitat enhancement crops. This article provides designs for trials with field and orchard crops for the first step of FAP projects. We share these designs, the initial results, and some arguments from contributing farmers to inspire more projects to assess the FAP approach.

\section{Material and methods}

The win-win situation underlying FAP is based on higher yields mainly by a greater diversity of alternative pollinators benefitting from the shorter distance between crop and enhanced habitat (Christmann and Aw-Hassan 2012). Prevalent methodologies using cages to measure the impact of pollination (e.g., Motzke et al. 2015) do not allow measurement of the value of habitat enhancement by comparing identical FAP fields (e.g., FAP 01-FAP 04) and non-intervention sites (control) concerning insect diversity and income. FAP research requires control fields providing free access to all 
available pollinators and predators. Control fields represent the prevailing type of fields characterized by intensive plowing, monocropping, and scarcity of weeds. The distance between fields should be at least $2000 \mathrm{~m}$ to avoid impacts from one field on others. Therefore, we conducted the cucumber trials in three villages stretched along a road and the sour cherry trials in two neighboring villages and two commercial farms on different hills.

\subsection{The design for trials with field crops on the example of cucumber as main crop}

FAP fields use $75 \%$ of the entire field for the main field crop and 5 cultivars with replications (Fig. 2). The design of the habitat zone considers that pollinators need, e.g., floral resources during three seasons, nesting and hibernating sites nearby, shelter against wind, and water resources, and farmers prefer high yields and low investment. The habitat zone encompasses $25 \%$ of FAP fields and includes

FAP Field

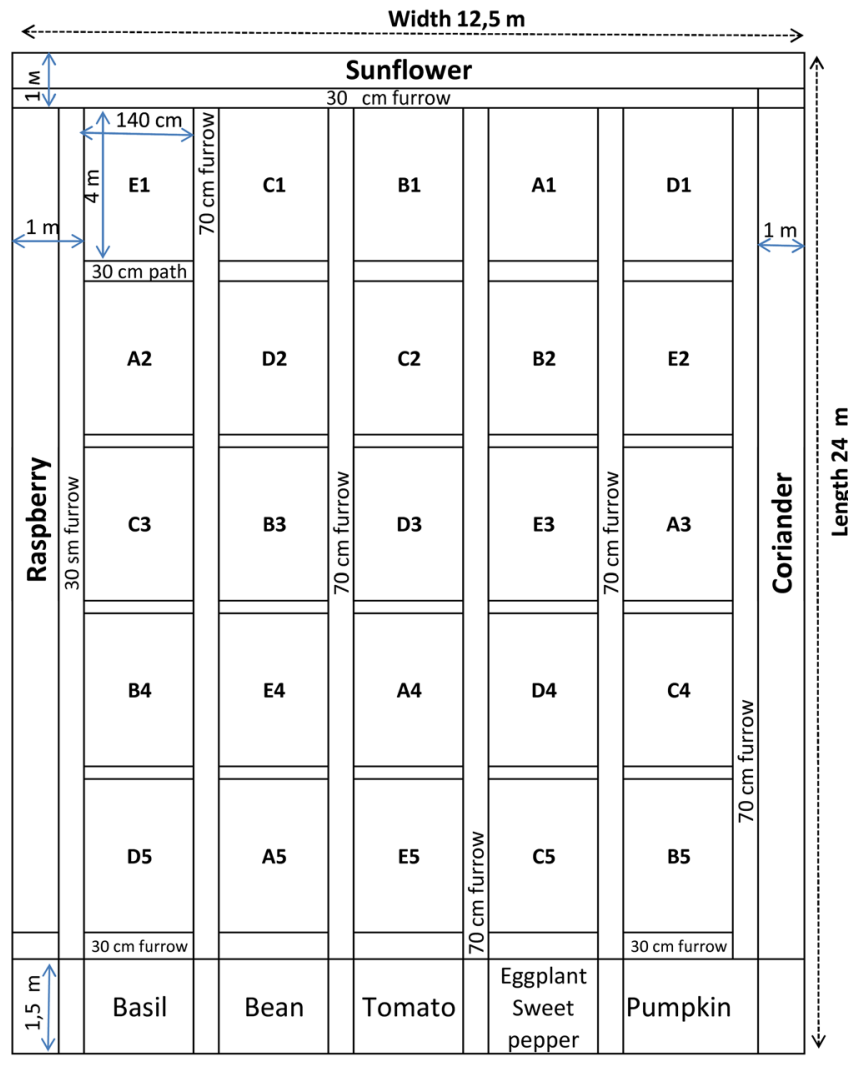

A - Uzbekistan-740; B -Ertagi-645; C-Navruz; D-Zilol; E-Zafar

1-5 replications

Fig. 2 Field sketch Parkent 2014: farming with alternative pollinators and control fields differ only in the $25 \%$ zones. Five cultivars and five replications in the $75 \%$ zones allow identification of the average impact of farming with alternative pollinators on the main crop and the best
1. A three-season forage buffet based on crops, herbs, spices, and medicinal plants to provide nectar and pollen at times when the main crop is not flowering and to attract a higher diversity of pollinators through different flower types and petal colors during the flowering period of the main crop

2. Nesting support of local materials such as fallow soil, reed, and dead wood with boreholes for different pollinator species

3. Crops providing shelter against wind

4. A small water puddle, which can be dug with a spade at the end of the irrigation furrow.

Control fields have a sixth cultivar of the main crop in the respective area (Fig. 2). The amounts of dung, irrigation, use of chemicals, and the agricultural practices can be determined by the farmers. However, after the decision has been taken, all farmers must adhere to the same practice. These investment costs do not cause a difference between FAP and control

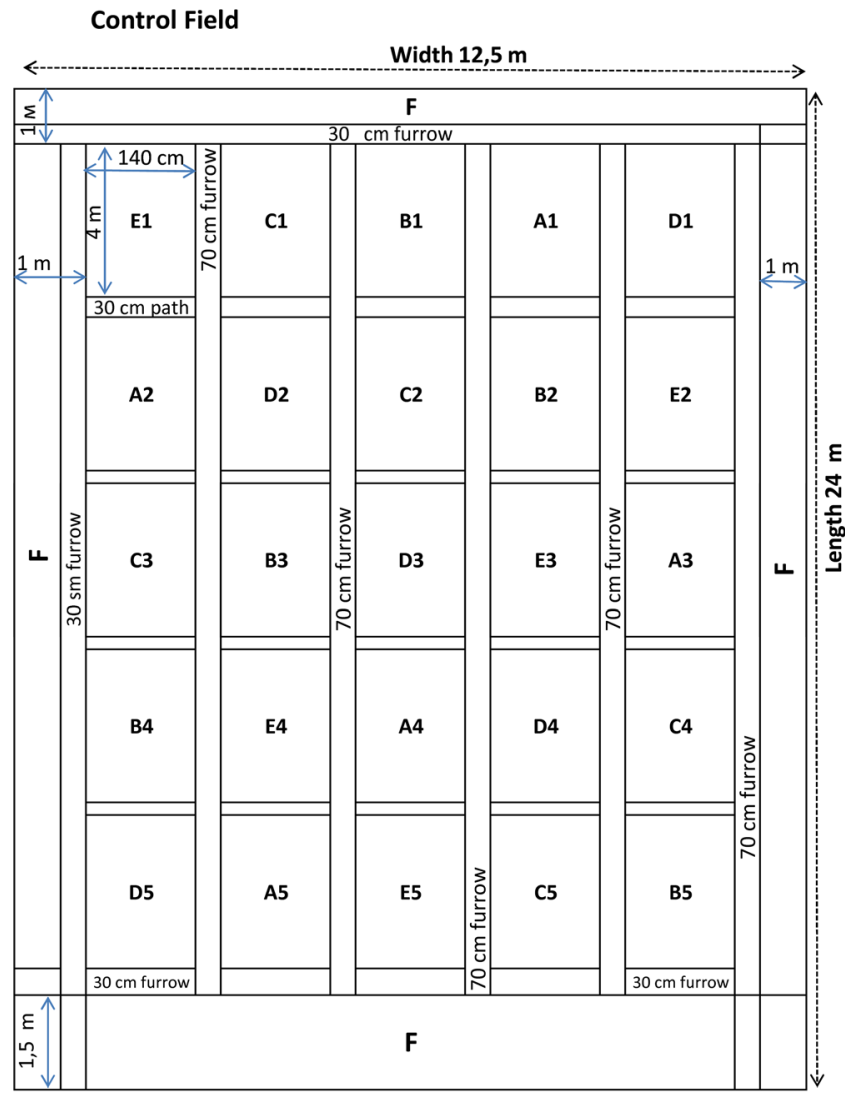

A - Uzbekistan-740; B - Ertagi-645; C -Navruz; D -Zilol; E -Zafar; $\boldsymbol{F}$ - local variety of "Uzbekistan"

1-5 replications

responding cultivar. FAP-fields: $A$ Uzbekistan-740, $B$ Ertagi-645, $C$ Navruz, $D$ Zilol, $E$ Zafar, $1-5$ replications. Control-fields: $A$ Uzbekistan-740, $B$ Ertagi-645, $C$ Navruz, $D$ Zilol, $E$ Zafar, $F$ local variety of "Uzbekistan," 1-5 replications 
fields. We stayed in very close contact with farmers and fields. Abundance of honeybees should be equal. As FAP fields attract more predators than control fields, it is necessary to identify pollinators, predators, and pests. In 2013, we collected insects only by transect, in 2014 , additionally by malaise traps for a 24-h assessment.

We based the economic assessments on the difference between FAP and control fields on the following factors:

1. The harvest of the main crop including number of fruit, weight of harvested crops, and price per kilogram as an outcome of quality based on shape, color, and taste. The number of fruit and the quality are indicators of effective pollination (Christmann and Aw-Hassan 2012; Garibaldi et al. 2013)

2. The income based on amount and price per kilogram or calculated benefit in the case of forage of the habitat zone or the sixth variety respectively reduced by the specific investment costs for seeds and seedlings for these zones. As the fields were small -0.02 ha in 2013 and 0.03 ha in 2014 and managed by household members, the farmers did not pay for labor. We calculated the additional labor costs for the habitat zone to better understand the feasibility of FAP. Larger-scale FAP trials with commercial producers should include labor costs into the economic assessment.

Among globally grown vegetables, we selected cucumber as main field crop, because of its long flowering period and the fact that the impact of pollination is "great" for this crop (Klein et al. 2007 define great as "animal pollinators are strongly needed (40-<90\% reduction)"; Appendix 2).

In 2013, we used maize, runner bean, and sunflower as shelter plants, pumpkin, eggplant, tomato, lavender, rosemary, coriander, sainfoin, topinambour, sweet sorghum, and faba bean for the three-season forage buffet on the four edges of the field and small strips between cucumber rows for habitat enhancement. Figure 2 shows the modified field sketch used in 2014 including all habitat plants.

\subsection{The design for trials with orchard crops on the example of sour cherry as main crop}

We used established orchards and developed a procedure for orchard crops: (1) select comparable orchards for FAP and control; (2) select a number of trees comparable concerning age, health, irrigation, and exposure to sun, e.g., six trees in an area of 0.03 ha; (3) choose twigs on similar level and with similar exposure to sun., e.g., five per tree; count a similar number of flowers, e.g., 50 flowers per twig starting from the end of the twig, place a marker, e.g., coloring or yarn; (4) count at different times the number of established fruit; and (5) check weight, quality, and price during harvesting.
We chose sour cherry as the orchard crop due to its great pollination impact (Klein et al. 2007, Appendix 2). Sour cherry has abundant flowers, and pollination is at risk due to increasing seasonal abnormalities in spring. We employed four sites: two school gardens managed by teachers and two commercial farms. We used abovementioned nesting support, hyacinth and crocus, because we were unable to plant, e.g., early flowering almond due to the short duration of the project, currant, sweet pepper, cucumber, sunflower, eggplant, coriander, safflower, basil, tomato, pumpkin, and buckwheat in the plowed areas between trees. The control orchards had uncovered soil. The data analysis for sour cherry was done using the $t$ test for two-mean comparison (FAP and control fields, independent samples).

\subsection{Assessing farmers' perceptions}

The village Avlod, 56 households, had a FAP-sour cherry site in their school garden. Here, we examined potential change of perceptions: ex ante by a participatory "Timeline" workshop (Chevalier and Buckles 2008) with randomly selected 13 women and 8 men between 20 and 80 years and ex post with short standardized interviews, which were distributed to 50 randomly selected adults.

\section{Results and discussion}

The described FAP experiments on two crops do not confirm assumptions that adding more flowers might lead to reduced pollination of the main crop (Carvalheiro et al. 2014).

\subsection{Impacts of FAP on income from cucumber fields}

In 2013, we worked with two farmers (one FAP, one control) from different villages in Parkent district. Farmers doubted positive impact of FAP on total field income. Therefore, we compromised on field plots of only 0.02 ha in total with three replications of each cultivar in the $75 \%$ area to gain initial data and response from the FAP farmer to develop the final field sketch for 2014. The soil of the control field was better than the soil of the FAP field regarding $\mathrm{K}_{2} \mathrm{O}, \mathrm{P}_{2} \mathrm{O}_{3}$, and $\mathrm{NaNO}_{3}$. During the flowering of cucumber, the FAP field had seven different pollinator species (including honeybees and wild bees of the genera Halictus and Osmia) and two different predators, while the control field had only one honeybee and only one Halictus sp. as pollinators and no predators. Pests caused about $20 \%$ of harvest loss in the control site, whereas the FAP site was not affected. Cucumbers were harvested at the time/size of the best market price with an average weight of $105.5 \mathrm{~g}$. In the $75 \%$ zone, the FAP field produced 1607 high-quality cucumbers, whereas the control field had only 368 mostly of low quality. Calculated for total field size of 
1 ha in USD, the income of the FAP field highly exceeded the income from the control site. The FAP field had USD 4149 derived from the $75 \%$ zone and USD 2669 from the $25 \%$ zone, the latter mainly derived from sunflower, maize, and pumpkin, which resulted in a total of USD 6818 , whereas the control field had a total of only USD 840. Even if the calculated labor costs for seeding, nesting support, and harvesting (equivalent to a full day of not heavy field work, per ha USD 619) would be included, FAP created an incentive for habitat enhancement.

In 2014, we collaborated with six farmers in three villages using four FAP fields and two control fields. The fields had similar soil quality. We used only the four edges for habitat enhancement (Figs. 1 and 2) to facilitate farmers' work, but due to larger field size of $0.03 \mathrm{ha}$, we planted five cultivars of the main crop in five replications. In 2014, it was difficult to find control farmers in the three project villages in Parkent district as farmers had communicated the income gain in 2013. We could not use the data of the second control farmer. Aware of the results from 2013, the farmer had planted tomato and other flowering crops all around the control field. The readiness for adoption was high.

However, in 2014, shortly after cucumbers set fruit in all FAP fields, but not yet in the control field, the entire district of Parkent was affected by very short, but strong rain with a high load of atmospheric pollutants (i.e., dust) after a long period of drought. The same day, temperatures rose to around $40^{\circ} \mathrm{C}$ for about 1 week. This resulted in broad devastation of fields by Cladosporium cucumerinum and Aphis gossypii, affecting most aggressively peach and pear trees, cucumber, and even pumpkin. All FAP fields had pear and peach trees close by. Covered densely by aphids, leaves and shoots became deformed and yellow. Many cucumber plants rapidly stopped further flowering and yielding (Fig. 3a), while the control site was hardly affected. It had neither peach nor pear around, and the plants were not yet flowering or producing cucumbers at the time of the pest.

Raspberry did not sufficiently grow to provide a harvest in 2014. The habitat zones of the FAP fields were not affected by the pest, apart from (to a limited extent) pumpkin. Therefore, the FAP fields attracted up to 12 different pollinator species including very efficient species such as Halictus, Osmia, Andrena sp., and honeybees at the same time in one FAP field and up to four different predator species. The control field had only one-respectively two-pollinator species simultaneously and two predator species, but only in the beginning. In total and despite the pest, two FAP fields had the highest income as the crops of the diverse habitat zone provided more income than the sixth cultivar of the control field (Fig. 3b). The income from the $75 \%$ area of FAP-03 field was even higher than the respective income from the control field. This is also due to the fact that, stressed by the pest, each farmer made his own decision for optimal cucumber size at harvesting; e.g., FAP-03 farmer harvested with an average weight of cucumber of $121.19 \mathrm{~g}$, whereas the control farmer with an average weight of $75.10 \mathrm{~g}$. While quality and price of FAP-03 cucumbers were the same, large size cucumbers generally have a lower price in Uzbekistan. The habitat enhancement zones did not reduce the income (reported in Barral et al. 2015); on the contrary, the results from 2014 show that FAP can buffer against high income loss in the event of a major disease or pest attack on the main crop. This is an argument specifically for poor farmers, but it is not as convincing as the result of the first year.

The new field sketch reduced also the calculated labor costs to USD 275 per ha.

\subsection{Impacts of FAP on productivity of sour cherry}

The FAP sites attracted effective pollinators. The proportion of flowers turning into fruits was more than double compared to the control fields, leading also to a significant increase of total yield (Fig. 4). Fruit mean weight was not affected and equal in FAP and control fields. According to $t$ test, FAP significantly increases yields of sour cherry: $\alpha=0.05$.

\subsection{Insight into farmers' perceptions}

All participating farmers regarded pollination as a service for granted; none of them employed managed pollinators. In particular, in Boysun, a district with large-scale commercial government-run honey production from Soviet times, many
Fig. 3 Comparison of harvest and income from cucumber fields 2014. a Harvest days of cucumber in $75 \%$ zone and grade of affectedness by aphids, Parkent 2014. b Total net income in USD per hectare from cucumber fields in Parkent 2014 a

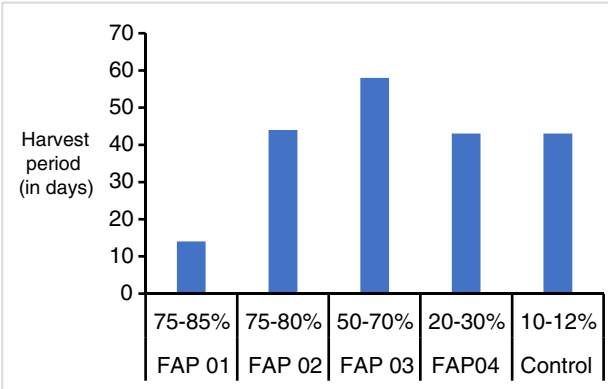

b

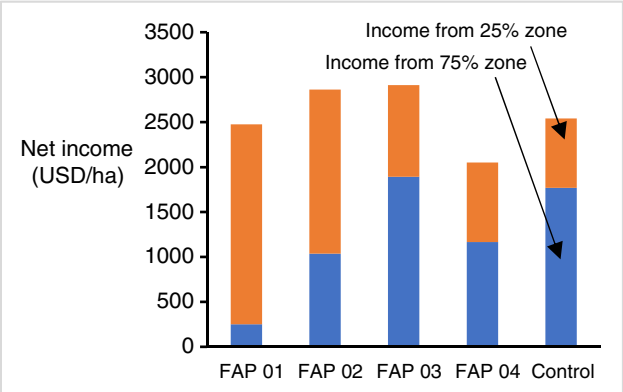


Fig. 4 Comparison of harvest from sour cherry 2014

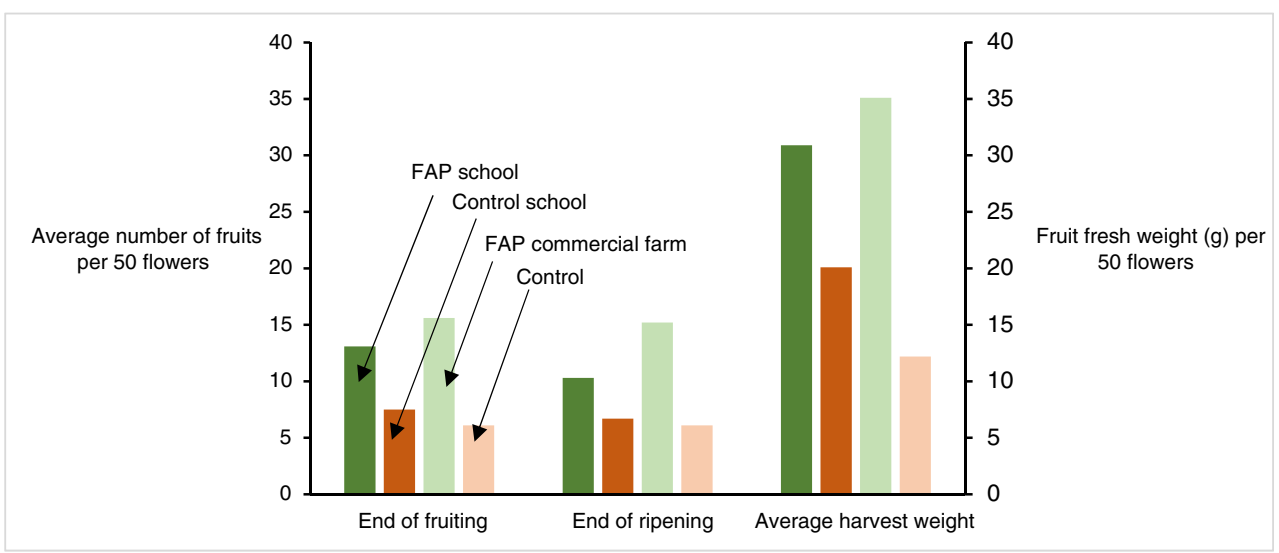

smallholders regarded only honeybees as pollinators. While wild pollinators were regarded as insects living around, the villagers had not realized that these alternative pollinators provide most of the service, in particular since the honey production had collapsed and beekeeping has become rare.

During the Timeline workshop, participants realized for the first time that the butterfly diversity had decreased by estimated $75 \%$ since the 1950 s parallel to logging forest and loss of floral resources, in grasslands also due to overgrazing. While $30 \%$ of the participants of the workshop stated they were not ready to enhance pollinator habitats "just for the next generation" (minutes of the workshop), 60\% declared to be willing to do so if the project can prove higher yields by habitat enhancement. The teachers of the secondary school in Avlod included the FAP site in their school garden and used posters on the importance of pollinators and their habitat demands into their lessons. As a result, all households were well informed. Many parents visited the school garden to inform themselves. After villagers were informed about the yield gap between FAP and control sites concerning sour cherry and cucumber, their readiness to enhance habitats increased to $94 \%$ according to questionnaires filled by 18 men and 17 women of 35 households.

In 2014, several participants of a training measure for village leaders from Parkent district themselves organized village meetings in their communities and passed on their new knowledge to farmers. In 2014, the small producers of the project villages knew that the habitat zone requires some additional labor, but they regarded it as unimportant in comparison to the potential yield increase.

Based on the results concerning harvest, we discussed the issue of higher labor for the habitat zones with the two participating large-scale commercial farmers in Boysun. The control farmer declared that the higher yield would exceed the investment in additional labor costs and that labor would be available. The FAP farmer, a reputed philanthropic man, stated that while he would provide all input and pay for the labor, he would give the harvest of the habitat plants for free to his workers, as he would not be interested in dealing with so many crops. However, one can conceive also the worst practice: reduced cash payment for workers as the harvest from the habitat zones is counted as in-kind payment. For large fields, we suggest a habitat zone on the edges of the field and a narrow strip of, e.g., $0.50 \mathrm{~m}$ every $25 \mathrm{~m}$ (Kohler et al. 2008; Ricketts et al. 2008) using the most efficient habitat plants. The optimal percentage of land required for the habitat zone should be identified.

In both project areas, we participatory developed the habitat zone. We did not ask farmers for entire wildflower strips, but the habitat zone could also include some wildflowers. All participating farmers rejected provision of any agricultural land for wildflowers, such as wild carrot, thistle, mullein, and cornflower. They categorized them as weeds, which do not provide an income, but bear the risk of spreading into the cropping area. They preferred and suggested crops, herbs, and medicinal plants, which all provide direct benefit. In Boysun, they accepted crocus and hyacinth as they understood the constraints of the short-term project, but they explained that they would not do accordingly. Without a participatory approach, scalable results might not be feasible. Farmers are the decision makers on their land. If, for example, they prefer faba bean or sainfoin instead of wild vetch among Faboideae, or welcome coriander and dill, but reject wild carrot among Apiaceae, it makes sense to seed the marketable plants and prove the impact of enhanced habitats on yields. In both project areas, higher yields and incomes were the farmers' criteria in assessing the approach as beneficial. The readiness to support pollinators based on this incentive highly exceeds the willingness of around $50 \%$ of farmers based on information as estimated by Kasina et al. (2009) and the ex ante assessment in Avlod. Nevertheless, the experience of Avlod supports the recommendation (Kasina et al. 2009) to involve the educational sector in pollinator protection.

In order to shift the pollinator protection to farmers, we recommend starting with women managing household plots or fields for subsistence, as they use no or little chemicals. In both project areas, women have also been interested in the additional crops to enrich the family diets. Due to their high number, smallholders can be important protagonists for 
pollinator protection. The low cost for habitat enhancement makes FAP attractive to resource-poor farmers.

\section{Conclusion}

Final conclusions require more research. Nevertheless, the project indicates FAP as a suitable approach to combat the global pollinator crisis since a habitat zone of marketable plants is acceptable for farmers. Global introduction of FAP might contribute to food security and reverse the trend of low and unstable yields of pollinator-dependent crops, currently compensated by increase of area (Aizen et al. 2009) or addressed by breeding pollinator-independent crops (ChaplinKramer et al. 2014). We recommend FAP for pollinatorfriendly intensification of horticultural production and as a farmer-friendly alternative to the most promoted seeding of wildflower strips for pollinator protection.

Acknowledgements The project was funded by The German Federal Ministry for the Environment, Nature Protection and Nuclear Safety within the International Climate Change Initiative (IKI).

\section{References}

Aizen MA, Garibaldi LA, Cunningham SA, Klein AM (2009) How much does agriculture depend on pollinators? Lessons in long-term trends in crop production. Ann Bot 103:1579-1588. doi:10.1093/aob/ mcp076

Barral MP, Benayas JMR, Meli P, Maceira NO (2015) Quantifying the impacts of ecological restoration on biodiversity and ecosystem services in agroecosystems: a global meta-analysis. Agric Ecosyst Environ 202:223-231. doi:10.1016/j.agee.2015.01.009

Biesmeijer JC, Roberts SPM, Reemer M et al (2006) Parallel declines in pollinators and insect-pollinated plants in Britain and the Netherlands. Science 313:351-354. doi:10.1126/science.1127863

Blaauw BR, Isaaks R (2014) Flower plantings increase wild bee abundance and the pollination services provided to a pollinatordependent crop. J Appl Ecol 51:890-898. doi:10.1111/1365-2664. 12257

Carvalheiro LG, Biesmeijer JC, Benadi G et al (2014) The potential for indirect benefits between co-flowering plants via shared pollinators depends on resource abundance, accessibility and relatedness. Ecol Lett 17:1389-1399. doi:10.1111/ele.12342

Chaplin-Kramer R, Dombeck E, Gerber J et al (2014) Global malnutrition overlaps with pollinator-dependent micronutrient production. P Roy Soc B 281(1794) http://dx.doi.org/10.1098/rspb.2014.1799

Chevalier JM, Buckles DJ (2008) SAS ${ }^{2}$ : a guide to collaborative inquiry and social engagement. SAGE Publications, Los Angeles, London, New Delhi, Singapore

Christmann S, Aw-Hassan AA (2012) Farming with alternative pollinators (FAP) - an overlooked win-win-strategy for climate change adaptation. Agric Ecosyst Environ 161:161-164. doi:10.1016/j.agee. 2012.07.030

Feltham H, Park K, Minderman J, Goulson D (2015) Experimental evidence that wildflower strips increase pollinator visits to crops. Ecol Evol 5:3523-3530. doi:10.1002/ece3.1444
Gallai N, Salles JM, Settele J, Vaissière BE (2009) Economic valuation of the vulnerability of world agriculture confronted with pollinator decline. Ecol Econ 68:810-821. doi:10.1016/j.ecolecon.2008.06.014

Garibaldi LA, Carvalheiro LG, Leonhardt SD et al (2014) From research to action: enhancing crop yield through wild pollinators. Front Ecol Environ 12:39-447. doi:10.1890/130330

Garibaldi LA, Steffan-Dewenter I, Winfree R et al (2013) Wild pollinators enhance fruit set of crops regardless of honey bee abundance. Science 339:1608-1611. doi:10.1126/science.1230200

Hanes SP, Collum KK, Hoshide AK, Asare E (2013) Grower perceptions of native pollinators and pollination strategies in the lowbush blueberry industry. Renew Agr Food Syst 30:124-131. doi:10.1017/ S1742170513000331

IPBES 2016: Eardley C, Freitas BM, Kevan PG, Rader R. Individual chapters and their executive summaries of the thematic assessment on pollinators, pollination and food production (deliverable 3(a)). http://www.ipbes.net/sites/default/files/downloads/pdf/3a pollination_individual_chapters_20161124.pdf. Accessed $2 \overline{4}$ November 2016

Kasina M, Kraemer M, Martius C, Wittmann D (2009) Farmers' knowledge of bees and their natural history in Kakamega district, Kenya. J Apicult Res 48:126-133. doi:10.3896/IBRA.1.48.2.07

Klein AM, Vaissière BE, Cane JH et al (2007) Importance of pollinators in changing landscapes for world crops. P Roy Soc B 274(1608): 303-313. doi:10.1098/rspb.2006.3721

Kohler F, Verhulst J, Klink R, Kleijn D (2008) At what spatial scale do high-quality habitats enhance the diversity of forbs and pollinators in intensively farmed landscapes? J Appl Ecol 45:753-762. doi:10. $1111 / j .1365-2664.2007 .01394 . x$

Lever JJ, van Nees EH, Scheffer M, Bascompte J (2014) The sudden collapse of pollinator communities. Ecol Lett 17:350-359. doi:10. 1111/ele.12236

McCracken ME, Woodcock BA, Lobley M et al (2015) Social and ecological drivers of success in agri-environment schemes: the roles of farmers and environmental context. J Appl Ecol 52:696-705. doi: $10.1111 / 1365-2664.12412$

Motzke I, Tscharntke T, Wanger TC, Klein AM (2015) Pollination mitigates cucumber yield gaps more than pesticide and fertilizer use in tropical smallholder gardens. J Appl Ecol 52:261-269. doi:10.1111/ $1365-2664.12357$

Munyuli T (2011) Farmers 'perceptions of pollinators' importance in coffee production in Uganda. Agric Sci 3:318-333. doi:10.4236/ as.2011.23043

Nabhan GP, Buchman SL (1997) Services provided by pollinators. In: Daily G (ed) Nature's services. Island Press, Washington DC, pp $133-150$

Ollerton J, Winfree R, Tarrant S (2011) How many flowering plants are pollinated by animals? Oikos 120:321-326. doi:10.1111/j.16000706.2010.18644.x

Potts SG, Biesmeijer JC, Kremen C et al (2010) Global pollinator declines: trends, impacts and drivers. Trens Ecol Evol 25:345-353. doi:10.1016/j.tree.2010.01.007

Pywell RF, Heard MS, Woodcock BA et al (2015) Wildlife-friendly farming increases crop yield: evidence for ecological intensification. P Roy Soc B. doi:10.1098/rspb.2015.1740

Ricketts TH, Regetz J, Steffan-Dewenter I et al (2008) Landscape effects on crop pollination services: are there general patterns? Ecol Lett 11: 499-515. doi:10.1111/j.1461-0248.2008.01157.x

TEEB 2010: Kumar P (ed) (2010) The economics of ecosystems and biodiversity: ecological and economic foundation, Earthscan, London, Washington 